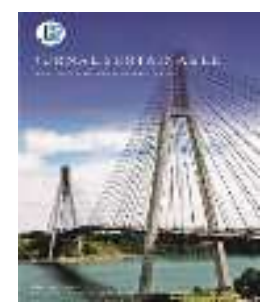

Jurnal Sustainable: Jurnal Hasil Penelitian dan Industri Terapan Vol. 07, No. 02, hal. 70-77, Oktober 2018

Jurnal Sustainable: Jurnal Hasil Penelitian dan Industri Terapan

ISSN 2615-6334 (Online) ISSN 2087-5347 (Print)

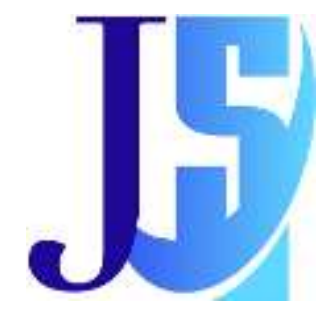

\title{
Sistem Kamera Pengamatan Bawah Laut Berbasis Teknologi Cloud Computing
}

\author{
Rozeff Pramana ${ }^{1, *}$, Eko Prayetno ${ }^{2}$, Sapta Nugraha ${ }^{3}$ \\ 1,2,3 Jurusan Teknik Elektro, Fakultas Teknik, Universitas Maritim Raja Ali Haji \\ ${ }^{1,2,3}$ Jalan Politeknik Senggarang, Tanjungpinang 29100 \\ *Corresponding Author: rozeff@umrah.ac.id
}

\begin{abstract}
The camera is a popular device and easy to find in every human activities nowadays. The camera is not only known in the world of photography to capture images and video, but more than that. The camera has been used monitoring device that helps human works easier, more effective and more efficient. The camera has been used for security, to monitoring a place, traffic monitoring and other similar function in various sectors of human activity. Even now, the camera has been integrated with computer system and other systems to create a sophisticated automation control and monitoring technology. The purpose of this research is to design an underwater monitoring camera system that can display good quality video of underwater objek which can be displayed and accessed via internet using Youtube application. The main component of this design consists high resolution waterproof camera, microtic device, and computer. The communiction media used to access the internet network of this device uses 3G/LTE cellular signal. This devise produces good quality underwater video. The farther the camera is placed in the sea, the less the lighting and it results blurred image and limited range of vision.
\end{abstract}

Keyword: Camera, underwater monitoring, cloud computing, Youtube, Internet.

Intisari- Kamera saat ini merupakan perangkat yang sangat popular dan mudah dijumpai dalam berbagai aktifitas manusia. Kamera tidak hanya dikenal pada dunia fotografi untuk mengabadikan suatu gambar/video, namun lebih dari itu kamera sudah difungsikan sebagai perangkat pengawas/monitoring yang membantu kerja manusia menjadi lebih mudah, efektif dan jauh lebih efisien. Kamera telah difungsikan untuk keamanan, pengawasan/pengamatan suatu tempat, pengawasan lalu-lintas, dan fungsi lainnya yang sejenis pada berbagai sektor aktifitas manusia. Bahkan kini, kamera telah terintegrasi dengan sistem komputer serta sistem lainnya sehingga tercipta suatu teknologi kontrol otomasi dan monitoring yang canggih. Tujuan dari penelitian ini adalah merancang sistem kamera pengamatan/monitoring bawah laut yang dapat menampilkan video objek bawah laut berkualitas baik dimana dapat ditampilkan dan diakses melalui internet dengan aplikasi you tube. Komponen utama rancangan ini terdiri dari kamera waterproof yang beresolusi tinggi, perangkat mikrotik dan komputer. Media komunikasi yang digunakan untuk akses jaringan internet perangkat ini menggunakan sinyal seluler 3G/LTE. Perangkat ini menghasilkan video bawah laut yang berkualitas baik. Semakin jauh kamera ditempatkan didalam laut, semakin berkurang pencahayaan dan mengakibatkan pencitraan objek menjadi kabur dan jarak jangkauan penglihatan menjadi terbatas.

Kata kunci: Kamera, Pengamatan bawah laut, cloud computing, You tube, internet.

\section{Pendahuluan}

Kamera bawah laut saat ini belum dikembangkan secara intens seperti jenis kamera pengawasan lainnya. Hal ini menjadi suatu hal yang menarik untuk mengembangkan kamera pemantauan dengan sistem yang dapat memantau keadaan bawah laut. Kamera bawah laut tersebut dapat digunakan untuk pemantauan 
pekerjaan bawah laut, pariwisata, pemantauan terumbu karang, pemantauan ekosistem laut, pencemaran laut, perangkat penunjang penelitian, eksplorasi tambang dan lain sebagainya. Seluruh hal yang berkaitan dengan pekerjaan bawah laut akan sangat terbantu dengan adanya kamera yang dapat memberikan informasi visual keadaan dibawah air/ laut tersebut. Hal ini akan mengurangi resiko pada pekerja tanpa mengurangi output yang diharapkan.

Berdasarkan latar belakang dan permasalahan yang dipaparkan, maka perlu dicarikan solusi teknologi kamera yang tepat dengan kondisi wilayah untuk mendukung pengawasan dan pemantauan wilayah khususnya dalam air/laut. Sistem kamera yang akan dirancang diharapkan dapat mendukung kerja pihak-pihak terkait. Penelitian ini juga akan merancang sistem energi mandiri untuk mensupply daya bagi sistem kamera tersebut agar bekerja optimal.

\section{KAJIAN LITERATUR}

Penelitian atau kajian terkait pemanfaatan kamera sebagai perangkat pemantauan/pengawasan telah banyak dilakukan. Tidak hanya untuk pemantauan, kamera juga digunakan sebagai sistem keamanan, pengintaian dan lain sebagainya. Penelitian tersebut diantaranya adalah [1] mengkaji tentang status dan prospek dari pengamatan dibawah laut. Sistem pengamatan dibawah laut dapat dibagi menjadi dua, yaitu pengamatan aktif dan pengamatan pasif. Pengamatan pasif memerlukan sumber penerangan yaitu berupa cahaya matahari, sedangkan pengamatan akif sumber cahayanya berasal dari perangkat elektronik. Objek penelitian ini yaitu melakukan pengamatan pada hewan laut dan keadaan kontur bawah laut. Hasil penelitian dari sistem ini adalah terbentuknya sistem penerangan bagi teknologi surveillance camera dibawah laut. Pada penelitian ini diberikan solusi untuk aktifitas pengamatan bawah laut pada malam hari atau pada saat tidak ada cahaya matahari menembus daerah bawah laut.
Penelitian sistem instrumentasi untuk kamera bawah laut yang berfungsi sebagai pemantauan lingkungan hidup dibawah laut. Komponen-komponen pendukung yang digunakan seperti kabel yang dirancang sesuai kebutuhan dan kegunaan. Sistem komunikasi dua arah yang digunakan adalah berupa RS 232, yaitu dari konverter RS 232 ke sinyal optik dan konverter sinyal optik ke RS 232 yang dapat menghasilkan transfer data dengan berkecepatan tinggi. Hasil dari penelitian ini adalah terbentuknya suatu sistem dasar dari teknologi surveillance camera [2].

Penelitian selanjutnya menggunakan sistem instrumentasi kamera bawah laut untuk mendeteksi dan mengikuti objek yang bergerak. Penelitian ini juga menganalisa keadaan untuk lingkungan bawah laut. Hasil penelitian ini bermanfaat untuk memantau dan menganalisis habitat dibawah laut serta perangkat penunjangnya, berbagai jenis spesies ikan beserta ekosistemnya [3].

Penelitian selanjutnya yaitu melakukan monitoring dengan memanfaatkan video streaming melalui mobile device yang dapat dilakukan dimana saja dan kapan saja. Pada penelitian tersebut mobile device dapat digunakan untuk memonitoring kamera IP melalui video streaming menggunakan protokol RTSP dan HTTP [4].

Penelitian yang menggunakan teknologi kamera IP juga pernah dilakukan oleh penelitian lainnya [5]. Penelitian tersebut menggunakan jaringan radio wirelless yang berfungsi sebagai pemantauan kinerja karyawan dan sekaligus sebagai keamanan di kantor PLN Wilayah Suluttenggo. Teknologi radio wireless yang digunakan menghubungkan kantor cabang dan unit kerja ditempat yang berbeda. Kamera IP yang terdapat di kantor-kantor cabang dan unit kerja terhubung dengan kantor wilayah, sehingga pemantauan kinerja karyawan dan keamanan dapat dimonitoring.

Penelitian selanjutnya [6] merancang suatu sistem kamera bawah laut menggunakan kamera IP. Penelitian ini merancang sistem kamera yang dapat memonitoring gambar/video bawah laut 
dari jarak jauh secara wireless menggunakan komputer/smart phone dengan jarak jangkauan 1.5-2 km dan dengan user yang terbatas.

\section{Metode Penelitian}

\section{A. Metode Pengumpulan Data.}

1) Studi Literatur: Metode dilakukan dengan mempelajari kajian-kajian yang pernah dilakukan oleh peneliti sebelumnya terkait kamera pengamatan dengan bersumber dari buku, jurnal-jurnal, maupun prosiding yang relevan.

2) Observasi: Metode ini dilakukan dengan cara pengamatan langsung untuk mendapatkan permasalahan dan data sebenar, kemudian dilakukan pula survey dan beberapa percobaan untuk mendapatkan gambaran permasalahan yang ada.

3) Perancangan perangkat: Metode ini yaitu merancang konsep perangkat dan kemudian membuat perangkat sesuai dengan tujuan yang ingin dicapai.

\section{B. Perancangan Sistem}

Sistem Kamera Pengamatan Bawah Laut Berbasis Teknologi Cloud Computing yang dirancang secara umum terbagi atas dua bagian utama, yaitu bagian perangkat utama berupa kamera dan instrument pendukung dan perangkat monitoring. Perangkat kamera akan ditempatkan didalam air/laut yang desain sedemikian rupa sehingga dapat beroperasi didalam air/laut. Sedangkan perangkat monitoring berupa computer dengan jaringan internet yang berfungsi sebagai perangakat monitoring yang berada diatas permukaan laut (pelampung).

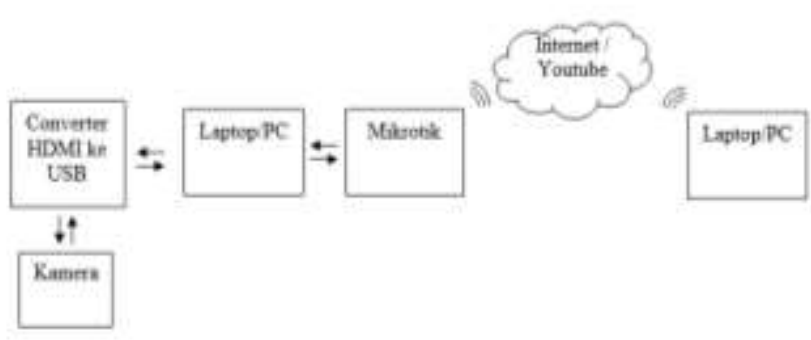

Gambar 1. Blok Diagram Sistem
Perangkat kamera utama pada penelitian ini akan ditempatkan didalam air/laut. Kamera khusus yang telah dimodifikasi akan ditempatkan pada tempat khusus pula sehingga dapat menghasilkan pencitraan yang baik. Guna dapat mengirimkan data ke bagian PC control yang berada di atas permukaan air, kamera akan dikoneksikan terlebih dahulu dengan menggunakan kabel ke bagian konverter HDMI ke USB agar data yang dihasilkan kamera dapat dibaca oleh PC. Selanjutnya PC akan mengirimkan data tersebut ke Internet dalam hal ini Youtube dengan menggunakan Mikrotik sebagai perangkat komunikasinya. Mikrotik tersebut ditempatkan di atas permukaan laut menggunakan pelampung yang didesain dan disetting sehingga mampu mendukung pengoperasian kamera yang berada dibawah laut.

Selanjutnya, mikrotik yang berada pada bagian permukaan laut tersebut akan mengirimkan data yang didapat dari kamera ke youtube. Media komunikasi yang digunakan adalah gelombang microwave. Video yang telah dikirim ke youtube dapat di akses oleh seluruh pengguna youtube dengan membuka akun penelitian yang telah didaftarkan sebelumnya.

Berikut adalah fungsi dari masingmasing perangkat yang akan digunakan:

1) Laptop/computer: Laptop/komputer yang digunakan sebanyak 2 buah. Yang pertama adalah perangkat yang digunakan untuk mengolah data hasil kamera ke mikrotik untuk dikirim ke youtube. Yang kedua adalah Laptop/komputer untuk monitoring hasil dari kamera bawah laut secara real time.

2) Mikrotik: Mikrotik adalah perangkat jaringan internet yang digunakan sebagai media perantara untuk menghubungkan laptop/komputer pengolah data dengan internet/youtube. Koneksi antara laptop/komputer pengolah data dengan router mikrotik menggunakan kabel UTP dan koneksi antara router mikrotik dengan internet menggunakan sinyal 3G/LTE.

3) Kamera: Kamera adalah perangkat yang digunakan untuk pemantauan keadaan bawah 
laut secara realtime. Data yang dihasilkan dari output kamera ini berupa data digital.

4) Kabel UTP: Kabel UTP berfungsi sebagai penghubung antara laptop dengan router mikrotik. Kabel UTP dirancang sedemikian rupa agar tidak masuk air.

5) Kabel HDMI: Kabel HDMI adalah kabel yang digunakan untuk mentransfer data hasil pencitraan kamera ke laptop/komputer pengolah data melalui konverter HDMI to USB.

6) HDMI to USB Converter: HDMI to USB Converter adalah perangkat yang digunakan untuk mengubah data yang didapat dari kabel HDMI ke kabel USB agar dapat dikenali oleh laptop/komputer.

7) Data/Informasi: Data/informasi yang dikelola pada perangkat rancangan ini nantinya adalah berupa gambar dan video yang berada disekitar kamera.

Berikut gambar diagram alir yang memaparkan penelitian yang akan dilakukan:

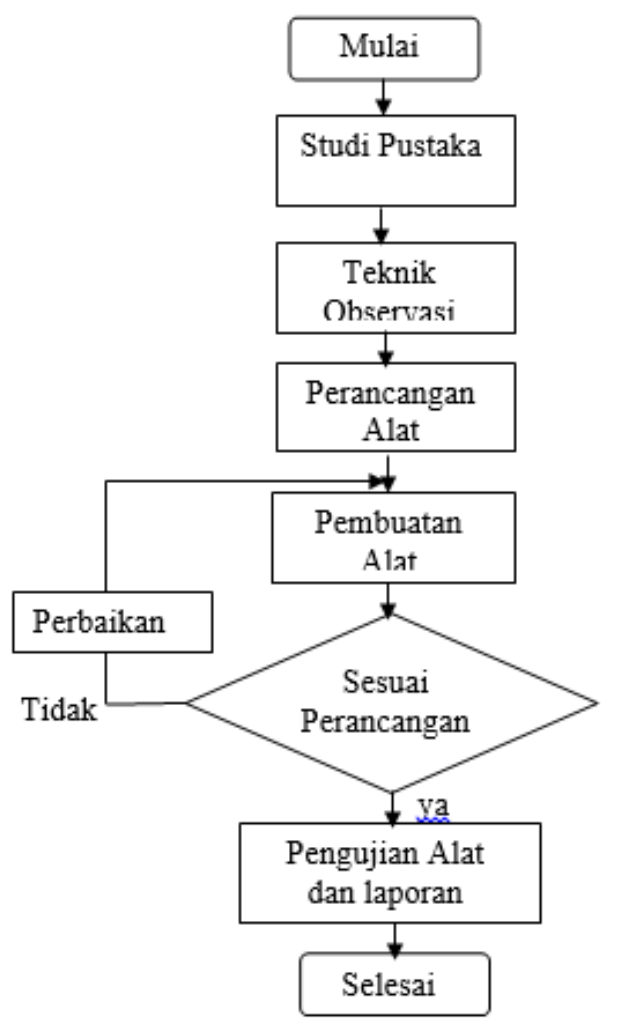

Gambar 2. Diagram Alir Penelitian

\section{Cara Kerja Perangkat}

Pencitraan suatu objek bawah laut yang ditangkap oleh kamera, akan diteruskan kebagian komputer sebagai pengolah data dengan kabel data HDMI dan USB melalui converter HDMI/USB. Kabel yang digunakan telah dimodifikasi dengan menggunakan perangkat pelindung berupa selang untuk melindungi kabel yang ditempatkan dibawah laut.

Data yang telah diterima oleh bagian pengolah, selanjutnya diteruskan ke perangkat mikrotik. Mikrotik pada perangkat rancangan ini berfungsi sebagai bagian pengirim data yang diterima oleh kamera bawah laut. Pengiriman data dilakukan dengan menggunakan jaringan telekomunikasi seluler dengan bandwidth yang tinggi untuk mempermudah proses pengiriman data.

Data yang dikirimkan oleh bagian mikrotik, akan dikirimkan ke internet. Sehingga pengguna dapat menerima tampilan data/video dengan menggunakan aplikasi video pada internet komputer, seperti Youtube.

\section{Perancangan Perangkat}

1) Perancangan perangkat kamera: Kamera yang digunakan pada perancangan ini adalah kamera jenis waterproof dengan resolusi yang dapat diatur hingga mencapai 4.3K. Kamera ditempatkan dalam suatu konsul (wadah anti air) dimana pada konsul tersebut terdiri dari kamera dan converter $12 \mathrm{~V}$ to $5 \mathrm{~V}$. Converter berfungsi sebagai pemberi supply daya bagi kamera yang bersumber dari battery 12 VDC yang berada diatas permukaan laut (diatas peampung). Converter tersebut terlebih dahulu mengubah tegangan 12 VDC dari battery menjadi 5 VDC sesuai tegangan operasi kamera.

Selanjutnya, koneksi antara perangkat kamera yang ada didalam konsul dengan bagian kontrol yang terdapat dipermukaan air laut (pada pelampung), dihubungkan menggunakan kabel HDMI. Kabel HDMI tersebut menghubungkan kamera dengan mini komputer dan mikrotik. Kabel HDMI tersebut diselubungi dengan selang anti air. Selain kabel HDMI, didalam selang 
tersebut juga terdapat kabel DC yang berfungsi men-supply energi bagi kamera dari battery yang berada diatas pelampung. Panjang kabel-kabel yang menghubungkan konsul dan bagian pelampung adalah sekitar $10 \mathrm{~m}$.

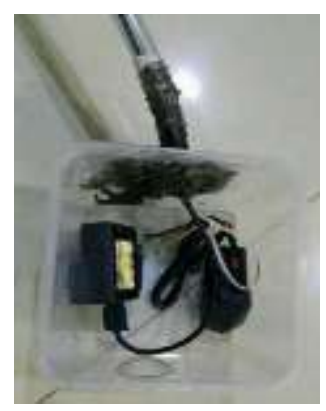

Gambar 3. Perangkat kamera pada konsul

2) Perancangan perangkat jaringan internet: Perangkat jaringan internet adalah perangkat yang berfungsi mengirimkan video dari hasil penerimaan kamera bawah laut untuk ditampilkan pada cloud computing. Pencitraan objek bawah laut dari kamera akan ditampilkan di internet melalui aplikasi video you tube. Perangkat jaringan internet dan pendukungnya pada perancangan ini ditempatkan pada bagian diatas permukaan laut yaitu pada pelampung. Perangkat jaringan untuk akses internet tersebut terdiri dari converter HDMI to USB, mini computer/PC/laptop, dan mikrotik. Koneksi antara laptop/komputer pengolah data dengan mikrotik menggunakan kabel UTP. Koneksi antara mikrotik dengan internet menggunakan sinyal seluler 3G/LTE dari salah satu operator seluler. Semakin tinggi sinyal yang bisa melayani mikrotik tersebut, semakin baik akses jaringannya.

Selain perangkat tersebut, juga terdapat perangkat pendukung lainnya yaitu 2 buah panel surya $50 \mathrm{Wp}$ jenis monocrystaline, battery control unit, dan battery.

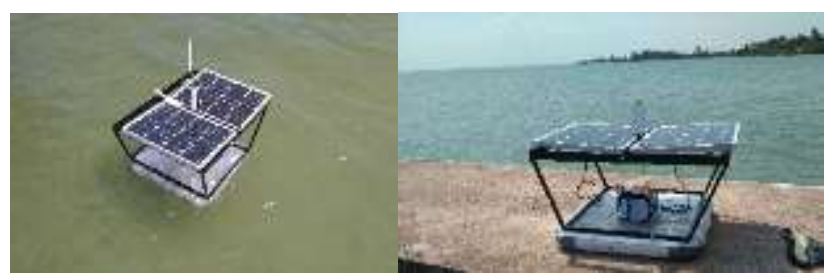

Gambar 4. Perangkat diatas permukaan laut

3) Perancangan perangkat monitoring: Untuk memonitoring hasil dari kamera, informasi yang dihasilkan oleh kamera akan ditampilkan di you tube internet, oleh karena itu perlu dibuatkan email google untuk bisa memiliki account you tube. Account yang didaftarkan untuk perangkat ini adalah penelitianelektroumrah@gmail.com.

\section{Pengujian Dan Analisis}

Pengujian perangkat dilakukan diwilayah perairan/ laut langsung pada kondisi sebenarnya. Kondisi cuaca pada saat pengujian dalam keadaan cerah, keadaan angin bertiup kencang dengan air laut sedikit bergelombang dan terdapat arus laut dari arah Barat daya lokasi pengujian. Perangkat ditempatkan langsung pada keadaan sebenarnya.

1) Pengujian perangkat Kamera: Kamera pada penelitian ini berikut konsul pelindungnya ditempatkan didalam air laut dengan diberikan pemberat untuk menahan posisinya agar tidak terbawa arus/gelombang.

Koneksi antara kamera yang berada didalam konsul didalam air laut dengan pelampung yang berada diatas permukaan laut, dihubungkan menggunakan kabel HDMI sebagai media pengirim data dan kabel DC yang merupakan pen-supply daya bagi operasional kamera yang bersumber dari battery dan solar panel yang berada dibagian pelampung diatas permukaan laut.

Kabel HDMI dan kabel DC untuk kamera dalam air tersebut dilindungi dengan selang anti air. Ini terbukti dapat melindungi kabel-kabel dari kemasukan air dan menambah ketahanan kabel agar tidak mudah putus bila terdapat arus didalam laut. Dari hasil pengujian diperoleh hasil sebagai berikut:

Tabel 3. Hasil pengujian kamera

\begin{tabular}{cccc}
\hline $\begin{array}{c}\text { Kedalaman } \\
\text { Kamera } \\
\text { (meter) }\end{array}$ & $\begin{array}{c}\text { Kondisi } \\
\text { console }\end{array}$ & $\begin{array}{c}\text { Jarak } \\
\text { pandang } \\
\text { Kamera } \\
\text { (meter) }\end{array}$ & $\begin{array}{c}\text { Respon } \\
\text { kamera } \\
\text { (Ya/Tidak) }\end{array}$ \\
\hline 1 & $\begin{array}{c}\text { Tidak } \\
\text { bocor }\end{array}$ & $3-4$ & Ya \\
3 & $\begin{array}{l}\text { Tidak } \\
\text { bocor } \\
\text { Tidak } \\
\text { bocor }\end{array}$ & $2.5-3$ & Ya \\
5 & $2-3$ & Ya \\
\hline
\end{tabular}


Saat pengujian, ketinggian kamera dari dasar laut diatur pada ketinggian 0-100 cm. Dari hasil pengujian tersebut diperoleh jarak pandang kamera yang tidak terlalu jauh. Dari beberapa kali pengujian yang dilakukan diperoleh hasil yang tidak jauh berbeda dengan jarak pandang maksimal sekitar 4 meter, walaupun kamera yang digunakan berkualitas baik. Hal ini dikarena kondisi laut bergelombang dengan terdapat arus laut, air laut secara kasat mata juga tidak dalam keadaan jernih dengan warna kehijauan. Hasil tampilan objek dari kamera juga dipengaruhi pencahayaan yang berada didalam laut.

Pencahayaan yang semakin berkurang pada kedalaman tertentu atau sinar cahaya matahari yang redup pada waktu tertentu, juga akan berdampak pada jarak pandang objek yang dicitrakan oleh kamera, walaupun resolusi kamera telah diatur tinggi. Selain hal tersebut, jarak pandangan kamera pada perangkat ini juga berkurang yang disebabkan karena material konsul kamera modifikasi yang digunakan kurang jernih.

Kondisi konsul sebagai pelindung kamera dan perangkat pendukung yang berada didalam air selama pengujian tidak didapati adanya kebocoran. Konsul kamera dengan mudah dimasukkan kedalam laut menggunakan pemberat, namun semakin dalam konsul dimasukkan kedalam air laut tekanan konsul tersebut semakin besar.

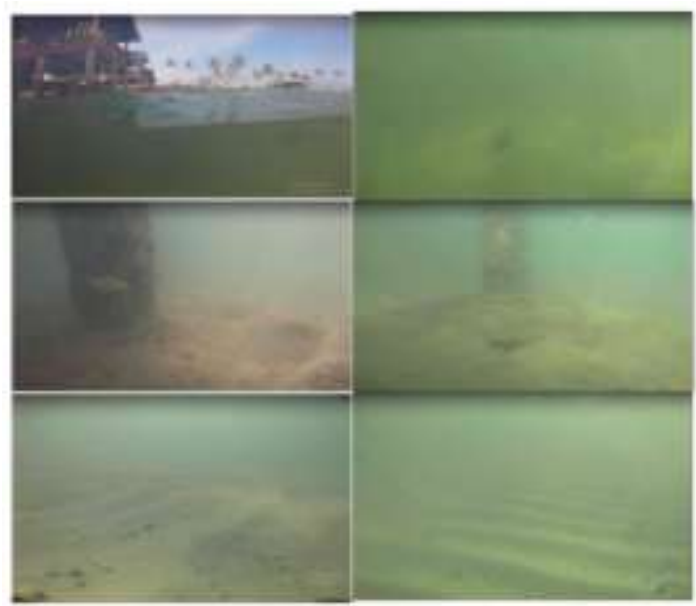

Gambar 5. Hasil tampilan kamera
2) Pengujian perangkat jaringan internet: Hasil pencitraan video yang direkam oleh kamera yang berada dibawah laut, selanjutnya dikirimkan ke perangkat mikrotik melalui kabel HDMI. Mikrotik terdapat dibagian pelampung yang berada diatas permukaan laut.

Koneksi antara laptop/komputer pengolah data dengan router mikrotik menggunakan kabel UTP, dan koneksi antara router mikrotik dengan internet memanfaatkan sinyal 3G/LTE dari salah satu operator seluler. Berikut hasil pengujian perangkat menggunakan jaringan seluler.

Tabel 2. Hasil pengujian perangkat jaringan

\begin{tabular}{cccc}
$\begin{array}{c}\text { Sinyal } \\
\text { Seluler } \\
(\mathbf{d b m})\end{array}$ & $\begin{array}{c}\text { Objek } \\
\text { tampilan } \\
\text { kamera } \\
\text { (Baik/Tidak) }\end{array}$ & $\begin{array}{c}\text { Pengiriman } \\
\text { Informasi } \\
\text { (Ya/Tidak) }\end{array}$ & $\begin{array}{c}\text { Tampilan } \\
\text { Internet } \\
\text { (Ada/Tidak) }\end{array}$ \\
\hline-60 & Baik & Ya & Ada \\
-85 & Baik & Ya & Ada \\
-97 & Baik & Putus-putus & Ada \\
-115 & Baik & Tidak & Tidak \\
\hline
\end{tabular}

Dari hasil pengujian dilapangan, objek bawah laut yang dicitrakan oleh kamera dapat dikirimkan dan ditampilkan pada aplikasi you tube diinternet bila Mikrotik sebagai perangkat pengirim data/informasi dari kamera mendapatkan sinyal seluler yang kuat dari operator. Bila sinyalnya lemah, informasi/video akan putus-putus dan proses pengiriman membutuhkan waktu lebih lama. Jika perangkat mikrotik tersebut tidak mendapatkan sinyal seluler, maka perangkat mikrotik tersebut tidak dapat mengirimkan hasil tampilan dari objek yang diterima oleh kamera. Dengan demikian, bisa atau tidaknya perangkat ini menampilkan hasil pencitraan kamera suatu objek dibawah laut untuk ditampilkan di aplikasi video di internet, bergantung pada jaringan seluler yang diterima oleh bagian pengirim/pengolah data dari perangkat ini. Untuk memastikan bagian ini berfungsi dengan baik, perlu diperhatikan kondisi sinyal seluler disekitar lokasi bagian pelampung dari perangkat ini. 
3) Pengujian perangakat monitoring: Informasi berupa video pencitraan dari kamera bawah laut yang dikirimkan ke perangkat mikrotik melalui sinyal seluler. Selanjutnya infomasi tersebut diteruskan ke Cloud Computing. Hasilnya dapat diakses dan dilihat melalui alamat

https://www.youtube.com/channel/UCjJ6mFEv DHUImF1wXKs4DZQ.

Video yang ditampilkan pada internet dapat berupa hasil video streaming maupun upload. Berikut tampilan hasil ujicoba video dari kamera yang dikirim pada you tube internet.

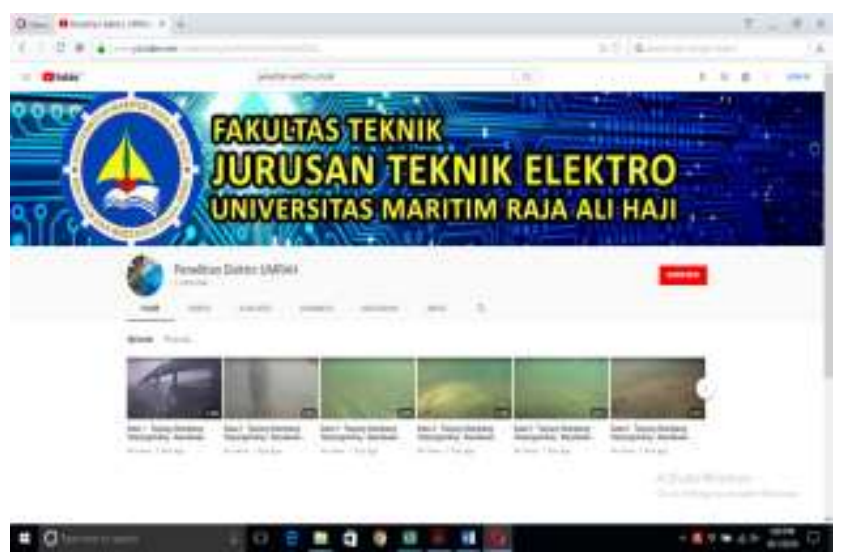

Gambar 6. Tampilan video pada Youtube internet

\section{KESIMPULAN}

1. Sistem kamera pengamatan bawah laut ini mampu mencitrakan objek bawah laut dengan jarak pandang 2 hingga 4 meter. Jarak pandang yang terbatas ini disebabkan kondisi laut sedang bergelombang dan ada arus laut yang mengakibatkan air laut tidak jernih.

2. Semakin dalam konsul kamera ditempatkan didalam air, pencitraan objek yang diterima kamera menjadi kabur karena semakin berkurangnya cahaya matahari didasar laut.

3. Keadaan air laut yang jernih tidak bergelombang akan menghasilkan objek video yang baik dan tidak bergoyang.

4. Semakin kecil ukuran konsul yang digunakan untuk kamera bawah laut, semakin kecil pula tekanan air yang diterima.

5. Sinyal seluler diperlukan oleh mikrotik pada perangkat ini untuk mengirimkan hasil video dari kamera menggunakan cloud computing.
Sinyal yang lemah mengakibatkan pengiriman menjadi terputus-putus dan menjadi tidak bisa dikirim.

6. Video objek bawah laut yang diterima oleh kamera dapat diakses dan dimonitoring oleh siapapun melalui you tube internet.

\section{UCAPAN TERIMA KASIH}

Ucapan Terimakasih setinggi-tingginya penulis sampaikan kepada Allah SWT atas Rahmat dan Karunia yang diberikan oleh-NYA sehingga jurnal ini bisa terbit. Ucapan Terimakasih juga kepada Universitas Maritim Raja Ali Haji yang membiayai penelitian ini hingga terlaksana.

\section{REFERENSI}

[1] Jules S. Jaffe, Karl D. Moore, John McLean, Michael P. Strand, "Underwater Optical maging: Status and Prospects:, Oceanogrhaphy, Volume: 14, No: 3, tahun 2001.

[2] Bradbeer. K. K. Ku, R. S., Lam. Y. L., dan Yeung. L. F., "An underwater camera and instrumentation system for monitoring the undersea enviroment", Proceeding 10th IEEE International Conference on Mechatronics and Machine Vision in Practice, hlm 189-194. Macau, Desember 2004.

[3] Bradbeer. R., K. K. Ku, Yeung. L. F., dan Lam. K., "An underwater camera for security and reactional use", Proceedings 9th Internasional Symposium on Consumer Electronics, hlm 364368. Macau, Juni 2005.

[4] Samuel Mahatma Putra, Handoko, Rika Mandasari, Bino Pramana Bestari, "Analisis dan perancangan aplikasi monitoring ip camera Menggunakan protokol http pada mobile phone", Seminar Nasional Aplikasi Teknologi Informasi 2010 (SNATI 2010), ISSN:1907-5022 Yogyakarta, tahun 2010.

[5] Zet C.J. Lawa, M.E.I. Najoan, ST., MT, A.S. M. Lumenta, ST., MT, dan M. Tuegeh, ST., MT, "Perancangan Teknologi IP Camera di Jaringan Radio Wirelless PT. PLN Wilayah Suluttenggo", Jurnal Teknik Elektro dan Komputer, Vol 1, No 3, tahun 2012. 
Pramana, dkk., Sistem Kamera Bawah Laut Berbasis Teknologi Cloud Computing

[6] Rozeff Pramana, Henky Irawan, "Sistem Kamera Pengamatan Bawah Laut", Jurnal Sustainable, Vol 06, No 01, hal 36-43, Mei 2017. 